\title{
Chinese Australian Urban Politics in the Context of Globalisation
}

\author{
Jen Tsen Kwok \\ The University of Queensland
}

\begin{abstract}
Globalisation and the rise of East Asia have accelerated the migration of Chinese populations across the AsiaPacific rim. Ethnic Chinese populations from highly diverse sub-ethnic, socio-economic and political backgrounds are increasingly aggregated in major cities throughout the region. Nonetheless, there remains insufficient attention to the implications of greater economic interdependence and accelerated population movement upon the political cultures of host nations such as Australia, especially in the context of ensuing spatial and economic concentrations of activity.

Both articulate and interlocking relationships between political and economic fields exist in the metropolitan engagements of Chinese Australian community groups and associations. Many of these political dimensions extend into 'formal' modes of politics.

Framed by urban regime theory and the broader notion of urban politics, this paper claims that network resource exchange within Chinese Australian communities are tied to ethnic economies, and in certain contexts global processes. These kinds of social dynamics have implications for the expression of diasporic Chinese affinity and constructions of Chineseness. Explorations of transnational political tensions, in fact, highlight the diversity and potential fragility of diasporic interdependence within ethnic Chinese communities - communities that are persistently refashioned through new waves of migration and from different points of origin.
\end{abstract}

This paper seeks to advance these perspectives through a case study of a particular period of tension between two representative peak bodies in Brisbane, Queensland. Grounded in the testimony of elite political actors, it reflects upon the nature of ethnic Chinese community representation in contemporary Australia.

Globalisation is at play through the increasing rapidity of movement of peoples across countries and the increasing presence of non-permanent political actors in the Australian labour market and polity. In recognising some of the implications of globalisation for economic systems, it becomes necessary to investigate how cities integrate and harness radically mobile formations of domestic and transnational capital, along with social agents who are heavily engaged in transnational economic flows. The relationship between global processes and 'ethnic' or 'enclave' economies can be understood through the evolving scholarship on Chinatowns. In particular, the development of concepts such as the 'ethnoburb’ (Li 1998, 2006) and the ‘ethnopolis' (Laguerre 2000) have re-characterised ethnic enclaves as anchors for global processes and global cities as aggregations of transnational niches (Kwok 2008, 469). Re-characterisation of the enclave economy also implies the need to pay greater attention to the role of urban politics in providing processes of engagement between social agents embedded in these networks with those engaged in domestic political cultures (Stoker 1998, 126). 
Such an approach recognises the complex interdependence between political and economic settings, and expresses an interest in Chinese involvement in Australian politics in a sense that is neither confined to 'formal' (Lam 2004) nor 'conventional' (Barnes, Kaase \& Allerbeck 1979) forms of political participation. Instead of approaching 'the political' through an interest in electoral politics or the mobilisation of community groups and interests, this paper is focused at the interactions between social agents who operate through the apparatus of government. Our concern remains with the nature of Australian citizenship as experienced by social agents from minority perspectives, but turns to their differentiated experiences of the Australian political system. During an epoch of unprecedented global mobility, analysing Chinese Australian social agents and community organisations through such a lens repositions ethnicity-based community and civic formations as potentially classstratified through differentiated economic and transnational mobilities (Zhou \& Lin 2005).

The terrain of this discourse is a particular urban political approach called urban regime theory, what Clarence Stone defined as 'the informal arrangements by which public bodies and private interests function together in order to be able to make and carry out governing decisions' (1989, p.229). It should be emphasised that the usefulness of urban regime theory arises here for very specific reasons. Certainly, it does not presume that network arrangements - which tie social agents from enclave economies and from political parties (or government) together - are regimes in the sense that they lead to comprehensive influence, or control of political decision-making. Urban regime theory is useful for other reasons (see Stoker 1998, Mossberger \& Stoker 2001, p.813). The first reason is that an urban regime approach recognises the significance of informal networks rather than formal institutions; it thus looks to comprehend the structural bridges between public control of government and private control of economic resources. The second reason is that, while regime arrangements depend upon active collaboration, it assumes stable and durable relationships between urban elites and political actors (spanning successive governments) can be built, especially where they are tied together through global flows. The third reason is that urban regime theory denotes the significance of each particular metropolitan context. Implications for the relevant political culture by such arrangements become defined through network participants, and may be distinct in character depending upon the metropolitan location.

More broadly, an urban regime approach theorises cultural formations with urban density in mind, acknowledging the city as the domain where the citizenship and identity claims of groups are recurrently, and in some instances, competitively articulated. In addition, the 
spatial dimensions of interaction, between community or business leaders and formal political agents, recognises that much of the capacity in developing mechanisms of political access and transnational engagement requires support and endorsement by political decision-makers and authoritative bodies, at the state and local government level. Such an approach is guided by Saskia Sassen's $(1991,2006)$ research on the competition between global cities as nodes of the global economy, in particular, her analysis in relation to the transforming role of government. This trend she captures through the phrase denationalisation - a phenomenon that has occurred deep inside the nation-state gearing political authority towards global economic engagement.

These dynamics have important implications for citizenship and political inclusion from the vantage point of community politics and representation. It brings into stark relief the function of Chinese community leaders as cultural and political intermediaries; in particular, their capacity to distribute what Lake and Huckfeldt (1998) describe as politically-relevant social capital through their commitment to greater civic engagement. In this paper, I intend to explore the civic significance of urban politics through a case study that involves the competition for public legitimacy by two umbrella organisations in Brisbane, beginning near the end of 2005. The organisations involved were the Queensland Chinese Forum (QCF) and the Queensland Chinese Uniting Council (QCUC). ${ }^{1}$ This case study, in addition, demonstrates the potential relevance and impact of sub-ethnic diversity in shaping competing transnational political orientations at the urban political level.

\section{Chinese Australian urban politics amidst Brisbane’s demographic heterogeneity}

Numerous metropolitan locations around the globe support highly heterogeneous diasporic Chinese populations. In Australia, the diversification in nations of origin for Chinese migrants is evident following the Colombo Plan (1949-57), the abandonment of the White Australia Policy (1973) and the rise of multicultural Australia (Ho \& Kee 1988; Kee 1988; Ho \& Coughlan 1997). In thinking about the political formations of Chinese Australian actors and communities, what requires further attention is what happens when diverse populations each who claim, or are identified through, Chinese ethnicity - are brought or bound together.

\footnotetext{
1 Interview testimony in this paper has been extracted from a sample of 46 de-identified interviews collected between September 2005 and June 2007 for a doctoral thesis on the legislative recruitment and political incorporation of Chinese Australians. The interviews with QLD parliamentarians, political candidates, academics and community leaders occurred throughout this period of time.
} 
Though there has been a continuous Chinese presence in Queensland since the 1840s, the modern demographic landscape begins after the introduction of Australian multiculturalism, in the late 1970s when the first waves of migration from Indochina and Vietnam reached Brisbane (Ip 2005, p.68). Following the birth of organisations in the late 1970s and early 1980s - such as the Chinese Ethnic Broadcasting Association of Queensland, the Cathay Community Association (formerly the Cathay Club), and the Chinese-language newspaper Queensland Asian Business Weekly - there has been a significant expansion of community associations. There has been, for instance, a proliferation of Chinese-language newspapers; of organisational purposes extending from the Buddha's Light International Association to Chinese Christian churches; as well as a diversification of sub-ethnic associations from the Taiwan Friendship Society to the Mainland Chinese Society of Queensland. Though the Queensland Multicultural Resource Directory remains a highly fraught document (not the least since its Chinese listings exclude Taiwanese associations), it contained no less than 70 ethnic Chinese organisations in 2006-7 (MAQ 2009).

Let us spend a moment comparing patterns of sub-ethnic Chinese diversity between the national context and Brisbane. The 2006 Australian Bureau of Statistics (ABS) Census reintroduced a formulation of the ‘ancestry' category in an attempt to better aggregate migrant populations based upon ethnicity rather than mere language competence. ${ }^{2}$ It is not the purpose of this article to theorise about the robustness of the new category as a proxy for the inclusion of Australian-born Chinese. However, the category does enable us to analyse Australians who claim Chinese ancestry based upon country of origin. Chart 1, derived from the ABS census figures, indicates that in 2006 there were more Chinese Australians born in China than there were born in Australia. The chart accentuates that the largest sub-ethnic communities were the Mainland Chinese (30\%), the Hong Kong and Malaysian Chinese (10\%), followed by the Vietnamese Chinese (6\%), the Singaporean, Indonesian and Taiwanese Chinese (4\% each).

\footnotetext{
2 ABS, 2006, 2914.0 - 2006 Census of Population and Housing - Fact Sheets, (http://www.abs.gov.au/ausstats/abs@.nsf/Latestproducts/2914.0Main\%20Features235002006?opendocument\&tabname= Summary\&prodno=2914.0\&issue=2006\&num=\&view=, Retrieved 10 November 2010)
} 


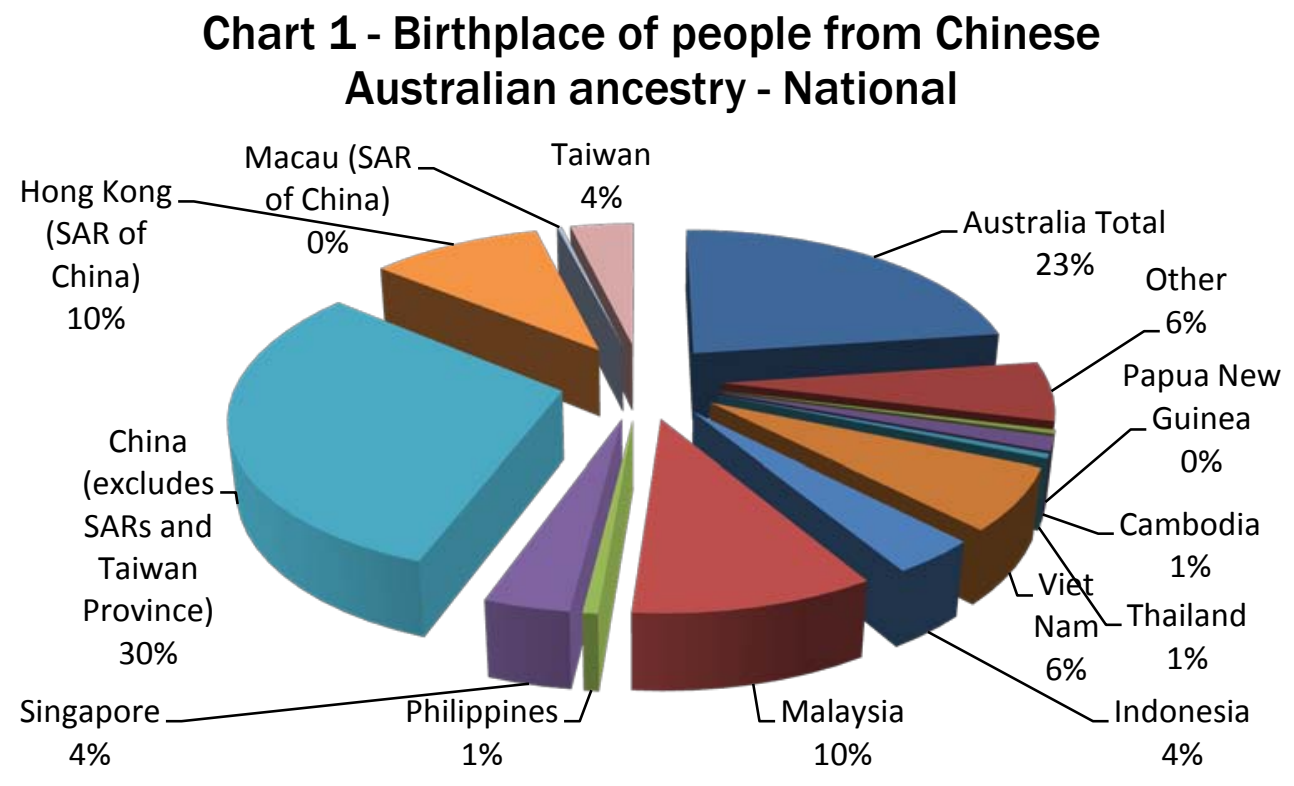

Data Source: 2006 ABS Census of Population and Housing

Comparing the national distribution to Brisbane, Chart 2 suggests that though the Australian (21\%), Hong Kong (11\%), Malaysian (8\%), Singaporean (4\%), Vietnamese (5-6\%), and Filipino (1\%) populations were similar, there were significantly less Mainland Chinese (22\% not $30 \%)$ and significantly more Taiwanese (17\% not 4\%) in Brisbane. There was also no notable Cambodian or Thai Chinese presence, though there was an identifiable Papua New Guinean Chinese community (3\%).

\section{Chart 2 - Birthplace of people from Chinese Australian ancestry - Brisbane}

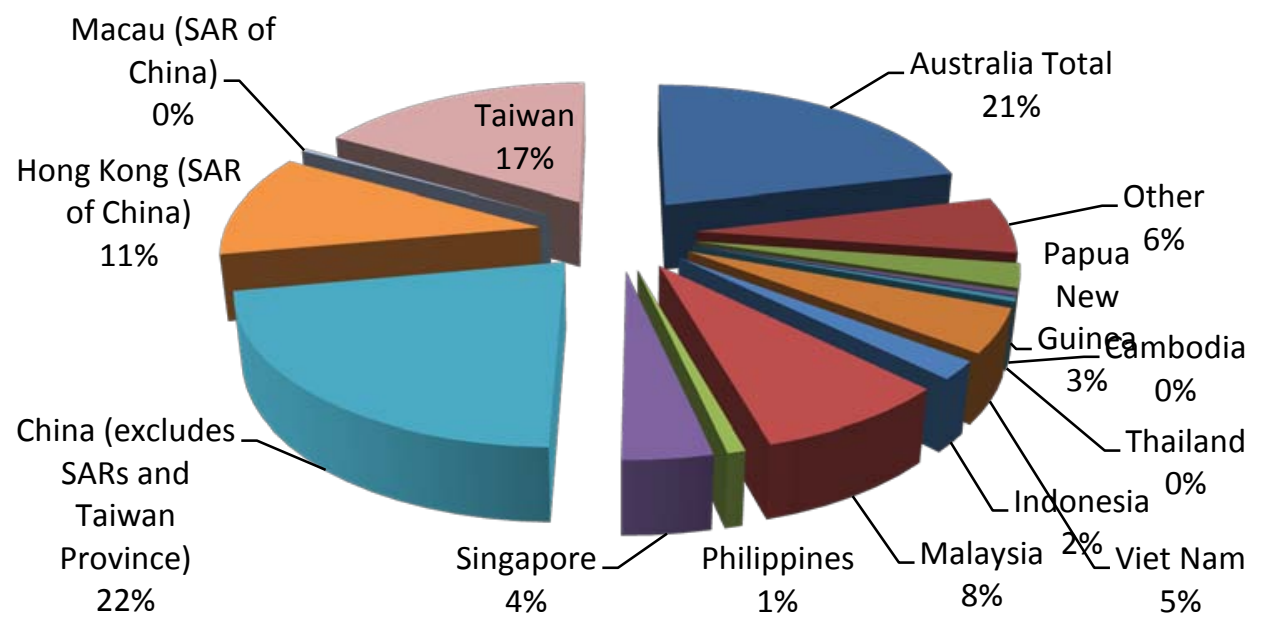

Data Source: 2006 ABS Census of Population and Housing 
The academic literature recognises the concentration of Taiwanese migration to Brisbane with Queensland being the state most populated by Taiwan-born Chinese, a trend that has emerged since the mid 1990s (Ip, Wu \& Inglis 1998; Ip 2001; Chiang \& Hsu 2005). The concentration of Taiwanese Chinese in Brisbane is notable in terms of the potential impact upon transnational political issues, particularly the 'cross-strait' issue (Lien 2006). Cross-strait or Taiwan-strait tensions refer to the international uncertainty over Taiwan's claims to independence from Mainland China and the prospects and conditions for Taiwan’s reunification.

Though it has often been construed as a matter of national identity, the primacy of this issue in Taiwanese democratic politics is entrenched by Taiwan's democratisation (Wu 2005), and the different stances of Taiwan's two leading political parties, the Kuomintang (KMT) and the Democratic Progressive Party (DPP). The KMT, Taiwan's oldest political party, whose origins lie in the democratic philosophies of Dr Sun Yat-sen, has progressively transformed its position on Taiwanese independence. This has emerged through political events such as the 'Pan-Blue' or KMT delegation that visited Mainland China in 2005 (including the fivepoint consensus signed on 29 April 2005 by both Hu Jintao and former KMT chairman Lien Chan on behalf of the KMT opposition), and more recently the Chen-Chiang Summits and the Cross-Straits Economic Trade and Culture Forum. In contrast, the DPP, whose establishment in 1986 followed Taiwan's democratisation in the early 1980s, has maintained a longstanding commitment to Taiwanese independence, a commitment that has been gradually nuanced according to the ‘special relationship' between Taiwan and Mainland China, as much as its opposition to the One China Policy.

\section{Legitimation crisis: the QCF versus QCUC dispute}

Amidst Brisbane’s demographic landscape the Queensland Chinese Forum (QCF) has existed in various forms since 1984, but was only formally incorporated in 1995. Though some delegates claimed it operated merely as a liaison group between organisations, QCF has sat at the apex of a changeable consortium of community-based, largely non-profit associations, located mostly in metropolitan Brisbane. It is what is commonly referred to as a 'peak' or 'umbrella' organisation, established to provide a space for community associations to engage with one another, and an entity to act on behalf of the Queensland Chinese community as a whole. 
Thus the establishment of the Queensland Uniting Chinese Council (QCUC) in late 2005 was significant because it initiated what Jurgen Habermas (1975) once described as a 'legitimation crisis' - a crisis over the capacity of QCF to coordinate dialogue and act on behalf of Queensland Chinese communities. In utilising Habermas's phrase, it is understood that he looked at legitimation specifically in relation to state governance and theorised about the role of a cultural system of legitimation necessary to elicit mass loyalty from citizens. Nonetheless, the phrase maintains a more general meaning. It also represents a situation where a governing structure retains formal authority to govern, but is not able to demonstrate that its practical operation fulfils its intended end. It is meant in this sense here. The competition between these organisations for endorsement, by the Queensland state government and the Mainland Chinese consulate in Brisbane, represented a substantial fracture in the urban politics of Chinese communities in Queensland.

In this dispute, allegations were made that QCF had provided inadequate community leadership. According to some this was for more than a decade. Its alleged precarious reputation was apparent in its incapacity to manage sub-ethnic political tensions; in particular, its alleged failure to accommodate greater Mainland Chinese integration into its membership structure. M, a QCF delegate intimated:

I'm also aware of now, through QCF, there's official difference (of) opinion between the Taiwanese group and the pro-China group. And I think we're at the moment (in) a bit of a stew because the Mainland China group wants to join QCF and so the current Taiwanese ones want to back off.

G suggested that the cross-strait issue had been an important source of political fragmentation amongst Chinese associations in Queensland, 'Even now there's already a split, in regards to Taiwan, Chinese, and Mainland Chinese. There’s already a split there'. H agreed, 'I mean, you can see a lot of activity will be totally organised and involved by one community and it's the other community will not be involved in it. And this is one thing which QCF is going to overcome'. Some attributed this fracture to an aggressive pro-independence stance held by certain groups within the Taiwanese community. G suggested, 'You know, we got some right-wing Chinese from Taiwan that is influencing others. Just one of those sad things to see happen. But what can we do? Except to try to pacify them, and try and work together with them as best as we could.' Others attributed it to competition amongst political party intermediaries for the support of sub-ethnic factions. 
QCF's domestic focus notably constrained its capacity to manage cross-strait tensions, with key QCF delegates emphasising that member organisations needed to set their transnational politics aside. H confirmed that QCF's focus upon domestic issues meant that it refused to take sides in the cross-strait issue:

Being the Chinese community (it) is inevitable that some of our people in Queensland are also active in terms of the political activity between Mainland China and Taiwan... This has been debated and discussed in QCF many, many times. And we make it quite clear that QCF are not, or will not, be involved in the political activity between Mainland China and Taiwan.

Others such as E emphasised a role for a peak body in managing the potential scope of this conflict:
'Eventually some issue will divide the Chinese community up into parts, like if there was someone stupid enough to push a button across the Chinese strait. That will immediately divide the Chinese community within an hour... within an hour of that happen segregation instated (sic). How do we manage that as a community?'

In contrast, counter-allegations claimed that QCUC's aims were almost exactly the same as QCF, and that it was initiated by a small group of community leaders with the intention of competing and eventually replacing the existing peak body. The prominent if not dominant role of Mainland Chinese migrants in the QCUC also raised questions about the organisation's capacity to host dialogue on cross-strait matters.

Comparison of the organisational aims strongly suggests that QCUC was started with the intention of competing for the peak representative role (QCF 2006; QCUC 2005). Some explicit differences are evident in organisational structure. The constituting documents confirm that QCF membership depended upon delegates from member associations. Where QCF's organisational structure primarily supports and enhances the capacity of associational leaders, QCUC could be considered more structurally inclusive as it also supports individual membership. The wording and priority of the two aims and objectives also highlight some divergence in organisational priorities. Where QCF's first political commitment is to the interests of ethnic Chinese organisations on domestic matters, QCUC's is more explicitly guided by the principles of better intra-organisational communication and the advancement of Chinese culture. Former president, Dr Su Mingxian, also publicly argued that QCF had not been adequate in developing Chinese diasporic political strength - defining a major purpose for the new QCUC as lifting the engagement of young people in the political process and increasing the number of Chinese Australians involved in Australian politics. 
Reflecting upon the significance of cross-strait tensions in Brisbane, it is important to recognise how poorly the symbolic ties of Chineseness constitute space for political solidarity. This is not only a dynamic problematised by the interactions between Chinese and host populations, but a reflection of the diversity of political attitudes based upon Chinese migration patterns themselves. The transnational dimensions of the cross-strait issue in Brisbane might be described as a kind of 'expanded transnationalism' (Vertovec 2009, p.18), resounding in political effects not only between Taiwanese Chinese and Mainland Chinese migrants, but with diffuse and uneven implications for enclave networks and the 'interlocking leadership’ structures that Flemming Christiansen (2003) described as emerging out of the associational system (119).

\section{Organisational competition based upon political access}

The case study is significant because the focus upon political capacity-building by QCUC meant that political engagement became a key area regarding the legitimation of QCF's peak status. QCUC had successfully invited ethnic Chinese political representatives, such as state ALP member for Capalaba, Michael Choi, and Federal Liberal member for Ryan, Michael Johnson, to QCUC as honorary patrons. This delivered the organisation important symbolic legitimacy and put into context the 2007 conference hosted by the QCF, called Australian Chinese, Australian Politics. This conference, held at State Parliament, effectively reinforced QCF's peak body legitimacy by providing a platform for not only Choi and Johnson but Coalition leader, Dr Bruce Flegg, and ALP campaign manager, Milton Dick, to address community members.

Also significant was the Chinese New Year function held earlier in 2007 by Premier Peter Beattie at Parliament House, an event which symbolically backed the QCF and its honorary president, Peter Low. H, in establishing the political credentials of QCF, looked to Premier Peter Beattie’s annual Chinese New Year function as a key example;

\footnotetext{
I'm not sure if we are the most politically active, but we are seen as very politically active. For example, QCF successfully lobbied the Premier for the last three or four years. He has been hosting a Chinese New Year function for the last three or four years in Parliament. Every Chinese New Year for the last three or four years he hosts a big function, inviting all the - I wouldn't say all over two hundred from the Chinese community to go to state parliament to celebrate Chinese New Year.
}

Since that time, the vociferousness of the dispute has diminished with the two peak organisations collaborating through activities such as the 2008 Beijing Olympics, fundraising 
for the Sichuan Earthquake and Queensland Flood Appeals. Nonetheless, the tensions which produced the dispute impart an important window into the competition for political access by elite community leaders, organisations and enclave networks.

The dispute between QCF and QCUC goes to the heart of the potential impact of transnational formations upon both the urban politics of globally-dispersed Chinese communities and domestic politics, in a more formal context. Through the transformation of political institutions, government and consulate representatives assume an important symbolic position as the imprimatur of formal institutions, and as its symbolic gate-keepers. In turn, the instrumental function of these leadership structures establishes routines for more concerted exchange and flow. Beyond the explicit role political actors may play in directly influencing the ecology of major cities, particularly in terms of property development, the kinds of activities and networks that strengthen business engagement, particularly through political access, define an important contested privilege - political access in itself represents a locus of contested urban political power.

This emerged as a much debated aspect of the conflict between the peak status of QCF and QCUC. Speculation arose that part of QCUC’s rationale for advancing the political prominence of a 'united' Chinese community was its interest in transforming or leveraging the business and trade relationship between Australia and China. In January 2006, Dr Su argued; 'In comparison with percentage of Chinese people in Queensland population and Chinese economic strength in the state, such a situation is not satisfactory.' D, a Mainland Chinese leader, privately asserted that business relations had not been a sufficient focus for QCF:

A lot of people know us. Even people in China know us. Consul people, embassy, know us, government know us, so they all want us to be part of them. But when I go to their (QCF) meeting I can see the job that they did - totally different. Totally different! QCF mainly focus on - let the Chinese community involve in Australian system (sic).

Consider also that at least seven of twelve delegates of QCF were, at the time, members of the Queensland China Council (QCC), a consultative body convened by the Queensland state government to facilitate trade through the promotion of political and cultural goodwill. The capacity of the body was based upon the late former Deputy Premier Tom Burns’ special relationship with the People’s Republic of China (PRC) politburo; a special relationship that stemmed from his involvement in the original and historic delegation of ALP members to 
Mainland China in 1971. Its activities have included routine delegations from China to Queensland, Queensland to China, and their mandate covers economic, educational and cultural network building. The overlap between the two is indicative of the bond between QCF leadership networks and representatives of the ALP government in Queensland, a relationship reinforced by trade and business opportunities.

Part of QCUC's rationale for advancing the political prominence of a 'united' Chinese community was its interest in gaining greater political access to these kinds of relationships and networks. Competition was underpinned by the distribution of substantive network resources through modes of political access, most of these having explicit economic and trade orientations. QCUC's public statements around the significance of the Chinese community's engagement in government-to-government trade networks failed to acknowledge that transformation of informal networks of access into modes of political influence are inconsistent with mainstream democratic values. In contrast, delegates of QCF made links between political access and influence, but overwhelmingly recognised the informal nature of this influence. Importantly, however, political access for some members of the QCF leadership was also a basis to promote personal, commercial, and in a few instances, political interests.

\section{Implications for Chinese Australian urban politics}

Chinatowns have persistently been sites for groups and political movements to push the barrow of political ideology. From political allegiances around the Hung League and Chinese Masonic Societies, which proliferated at the end of the $19^{\text {th }}$ century, to the Nationalist and Kuomintang movements of the 1920s and later, the transnational reach of Chinese political engagements is uncontroversial. Numerous scholars have enhanced historical insight into the texture of these political formations in Australia. For instance, Tian Ming Cai (1998) explored this through the Chun Wah association's unification of district and clan alliances, to oppose the effects of racism under the White Australia Policy. Likewise, John Fitzgerald (2006) more recently considered the role of Chinese Australians in shaping organisational orientations imbued with the character of Australian class politics. There is perhaps no more precise way to dispel the presumption that Chinese Australians are intrinsically less political compared to other migrant communities or populations.

Based upon the Brisbane case study, two crucial claims about the character of Chinese Australian urban politics emerge. The first stems from an expansion in the number of 
community organisations, as well as an expansion in their adaptive functions. The broadening array of organisational purposes has been triggered by major transformations in diasporic Chinese communities themselves (and the spaces that Chinese migratory populations inhabit). As Edgar Wickberg claimed, since World War II families have replaced sojourning males; Chinese immigrants have brought an increasing diversity of skills, resources and status; and migration is sourced from a growing multitude of nations and sub-ethnic backgrounds (1994, p.76). We might add to this observation, the lived dimensions of cultural 'hybridisation', which empower a greater range of social agents to cross group boundaries, and also implicitly creates the political space for boundary maintenance by various social agents.

This growing demographic heterogeneity poses important questions to community groups and (in particular) peak or umbrella organisations, in terms of their capacity to mobilise and represent communities. In relation to Chinese Australian urban politics, the 'contact zones' of global cities (Yeoh \& Willis 2005) produce complex, fluctuating networks of interlocking ethnic leadership in which group identities become sites for contested meaning. These are dependent not only upon racial marginalisation, migratory flows, but formations of domestic and transnational economic capability. We should also consider that, in some instances, there may be sufficient social stratification to establish diverse rights claims. This can relate to a community's symbolic resources as much as it can to identity or geographic space. As Tseen Khoo recognised in the cultural competition for urban space in Brisbane, 'Chinatowns have multiple, contested meanings for different sectors of the community, and no single function eclipses others' (2009, p.215). This does not deny the fundamental need for representative groups (especially representative groups that have political functions), but begs a question about the basis upon which legitimation of an organisation is centred. It is necessary to consider the kind of social resources an organisation deploys to justify the representation of a community or a group’s interests.

Secondly, the competition for political access and the outpouring of urban political conflict in this case study, highlights the tenacity of those specific network arrangements in bridging public and private spheres. We may consider the effects of globalisation upon the way we understand the Australian political system and the apparatus of government as actors in the global economic order. Chinese migrations have impacted upon the economic capability of major cities through the migration of transnational economic actors, the development of enclave economies, as well as a reorientation by major cities to the global dimensions of economic activity. These patterns create opportunities for new governance mechanisms and 
increasingly complex approaches to urban politics as the governing bodies of these cities adapt.

While this paper does not posit (as part of its approach to urban regime theory) an emptying out of governance functions, it does seek to reinforce the relevance of globalisation in the development of urban regime arrangements incorporating Chinese Australian community actors and organisations. According to Stone (2005, p.331), urban regime theory ultimately looks to understand how viable and durable arrangements for engagement and governance are created and claims the development of a regime is based upon at least the following three conditions:

- an agenda,

- resource adequacy, and

- an alignment of actors.

The conditions for the durability of a regime are further enhanced by 'selective incentives', which directly benefit network participants along the way (2005, p.320). Though Stone constructs urban regimes as largely 'contingent' (2005, p.325), he also recognises that regimes are 'structural' in the sense that they are compelled by structural forces such as those generated through global processes. Thus, in coming to terms with the global orientation of enclave economies, we can understand the recurrent potential for regime arrangements to emerge.

The significance of this for governmental and political agents - who are increasingly attuned to the role of ethnically-based enclave economies as anchors for global processes - implies increasing interest in modes of resource exchange that have little to do with the transfer of information or the intermediation capacity of non-elite immigrant organisations (Poppelaars 2007, p.20). The influence of the global economy emerges in creating the conditions for network arrangements that sustain durable and recurrent means of interaction, between public and private social agents vested in the economic development of enclave economies, and networks tied to international business and trade. In addition, social agents engaged in these kinds of network and regime arrangements, be they politicians, business or community leaders, may act or be coopted, as agents or interested parties, in building trade, business or government-to-government ties. These ‘opportunities' are likely to sustain themselves, whether or not trends in migration and multicultural scholarship are interested in political participation and civic engagement. 


\section{Conclusion}

The urban regime arrangements considered in this paper provide both opportunities and risks for the nature of Chinese Australian community representation. Engin Isin in Democracy, Citizenship and the Global City (2000) argued that the citizenship status of the foreigner swept up in the logics of global capital - is expressed in terms of a political struggle for presence. Isin implied that the new dimension of political struggle is not in defence of the traditional rights of property, but the right to claim presence, the right to access resources. This is a phenomenon brought about by an unbundling of citizenship rights in global cities constituted by political actors who have different investments in citizenship. While these ideas construct a moral landscape for the expansion of democratic participation, they also establish an apparatus supporting transnational economic flows and mobilities. And thus a durable urban regime can equally operate to entrench social inequality by excluding 'lowerstatus' groups (Stone 2005, p.328). The nature of fluctuating community leadership networks tie representation and political engagement to informal modes of political access based in enclave networks and economies. In this process, community elites compete not only for the right to represent, but the right to be present, greased by the networks that politicians and political parties often cultivate for fundraising, vote-catching and influencing constituents.

In exploring how regimes are established, Stone (2005) reconsidered the significance of agenda-setting as a structure for the agency of participants, and the need to comprehend the durability of a regime based upon its capacity to draw together the resources necessary to fulfil or implement such an agenda. This area is perhaps one of the great challenges for local and state governments, as well as political leaders in their engagement with urban politics. The agenda for the establishment of network arrangements between public and private ethnic business interests have often been framed by a symbolic commitment to a version of multiculturalism that has suffered from long-standing and broadly-accepted conceptual flaws. One has been its institutionalisation of difference and its reification of cultural expression, which has diminished the relevance of building democratic cultures through greater civic engagement, and in particular, the potential to utilise community resources to bridge gaps in the distribution of politically-relevant social capital. The second is that newer and supplementary concepts, such as ‘productive diversity’ (Bertone, Esposto \& Turner 1998), have in some instances allowed the economic and political dimensions of network engagement to be conflated. In numerous instances, such as in Brisbane, Queensland, this has 
bifurcated government priorities in relation to multicultural engagement towards more entrenched and more prosperous communities.

The final challenge is that settings within public discourse are a major constraint to exploring Australian citizenship in the context of globalisation. In spite of emergent discourses on postnational citizenship, our political identities remain tied to geography - we each remain citizens of somewhere. The citizen is a juridical, cultural and political status, a social position reflecting distribution of power and resources vested by the nation-state, but also a social boundary between us-and-them, arising because of migration or fortune of birth, managed by instruments of the state that range from constitutional protections through the enforcement of human rights covenants and trade agreements to the historical antecedents of national cultures. Pervasively human bodies are arbitrated between the inclusion and exclusion of a range of legal protections, in effect the rights and obligations secured by the formal boundaries of citizenship (Linklater 1998). Therefore, social inequalities can in fact be ingrained where social policies governing cultural difference fail to allocate proper recognition of the role of global processes in transforming urban and metropolitan landscapes. Certainly the international education market sits at this conceptual precipice. Current iterations of Australian citizenship, multiculturalism and social inclusion remain locked into modes of interpretation that are territorially-bound, at a time when they need to reorient to the effects of globalisation. The starting point would be deeper, smarter engagement through public discourse and political leadership about how Australia's future is tied to national myths and concepts at ease with cultural diversity, and leadership willing to commit to a notion of citizenship that actively seeks more diverse civic and political inclusion.

\section{Bibliography}

Australian Bureau of Statistics (ABS) 2006 Census of Population and Housing, C-Data Online, http://www.abs.gov.au/cdataonline, Retrieved 9 August 2010.

Barnes, S. H., Kaase, M. and Allerbeck, K. R. 1979, Political action: mass participation in five Western democracies, Sage Publications, Beverly Hills, CA.

Bertone, S. Esposto, A. and Turner, R. 1998, Diversity and dollars: productive diversity in Australian business and industry, Committee for Economic Development of Australia (CEDA), Melbourne.

Chiang, L. N. and Hsu, J. R. 2005, 'Locational decisions and residential preferences of Taiwanese immigrants in Australia’, GeoJournal, no. 64, pp. 75-89

Christiansen, F. 2003, Chinatown, Europe: An exploration of overseas Chinese identity in the 1990s, Routledge Curzon, London. 
Fitzgerald, J. 2006, 'Transnational networks and national identities in the Australian Commonwealth: the Chinese-Australasian Kuomintang, 1923-1937’, Australian Historical Studies, vol.37, no.127, pp. 95-116

Fong, T. P. 1994, The First Suburban Chinatown: The Remaking of Monterey Park, California, Temple University Press, Philadelphia.

Habermas, J. 1975, Legitimation Crisis (trans. Thomas McCarthy), Beacon, Boston.

Ho, C. H. and Coughlan, J. E. 1997, 'The Chinese in Australia: Immigrants from the People's Republic of China, Malaysia, Singapore, Taiwan, Hong Kong and Macau', in Coughlan, J. and McNamara, D. (eds) Asians in Australia: Patterns of Migration and Settlement, Macmillan Education Australia, Melbourne, pp. 120-70

Ho, C. and Kee, P. 1988, 'Profile of the Chinese in Australia', The Chinese in Australia: Proceedings of the Conference held on 19 March 1988, Centre for Migrant and Intercultural Studies, Clayton, Melbourne, no.12, pp.7-24

Ip, D. 2001, 'A Decade of Taiwanese Migrant Settlement in Australia: Comparisons with Mainland Chinese and Hong Kong Settlers’, Journal of Population Studies, no. 23, pp.113-145

Ip, D. 2005, 'Contesting Chinatown: Place-making and the emergence of 'ethnoburbia' in Brisbane, Australia', GeoJournal, no.64, pp. 63-74

Ip, D., Wu, C.T. and Inglis, C. 1998, 'Settlement Experiences of Taiwanese Immigrants in Australia', Asian Studies Review, vol.22, no.1, pp.79-97

Isin, E. F. 2000, 'Introduction: Democracy, citizenship and the city', in Isin, E. F. (ed), Democracy, Citizenship and the Global City, Routledge, New York.

Kee, P. 1988, Chinese immigrants in Australia: construction of a socio-economic profile, Institute of Applied Economics and Social Research, Parkville, Melbourne.

Khoo, T. 2009, 'Affirming Cosmopolitanism? Chineseness and the Chinese Museum of Queensland,' in Ho, E. Y. L. and Kuehn, J. (eds) China Abroad: Travels, Subjects, Spaces, Hong Kong University Press, Hong Kong, pp. 209-24.

Kwok, J. 2008, 'Clientelism in the ethnopolis: ethnic contribution networks and political fundraising under late multiculturalism', Journal of Australian Studies, vol. 32, no.4, pp. 467479

Lake, R. L. D. and Huckfeldt, R. 1998, 'Social Capital, Social Networks, and Political Participation,’ Political Psychology vol. 19, no.3, pp. 567-84

Laguerre, M. 2000, The Global Ethnopolis: Chinatown, Japantown and Manilatown in American Society, Macmillan Press, London.

Lam, W. 2004, Understanding the political culture of Hong Kong: the paradox of activism and depoliticization, ME Sharpe, New York.

Li, W. 2006, 'Introduction: Asian Immigration and Community in the Pacific Rim', in Li, W. (ed.) From urban enclave to ethnic suburb: new Asian communities in Pacific Rim countries, University of Hawai'i Press, Honolulu, pp. 1-22

Li, W. 1998, 'Ethnoburb versus Chinatown: Two types of urban ethnic communities in Los Angeles', Cybergeo, no. 70.

Lien, P. 2006, 'Transnational homeland concerns and participation in US politics: A comparison among immigrants from China, Taiwan, and Hong Kong', Journal of Chinese Overseas, vol. 2, no.1 pp. 56-78

Linklater, A. 1998, The Transformation of Political Community: Ethical Foundations of the Post-Westphalian Era, Polity Press, Cambridge.

Mossberger, K and Stoker, G. 2001, 'The Evolution of Urban Regime Theory: The Challenge of Conceptualization', Urban Affairs Review, vol. 36, no. 6, pp. 810-835

Multicultural Affairs Queensland (MAQ), QLD Multicultural Resource Directory, http://www.multicultural.qld.gov.au/media/maq_resource_directory.pdf , Retrieved 10 June 2009. 
Ong, A. 'Limits to Cultural Accumulation: Chinese Capitalists on the American Pacific Rim', Schiller, N. G., Basch, L. and Blanc-Szanton, C. (eds) Towards a Transnational Perspective on Migration: Race, Class, Ethnicity and Nationalism Reconsidered, New York Academy of Sciences, New York, pp. 135-6

Ong, A. 2006, Neoliberalism as Exception: Mutations in Citizenship and Sovereignty, Duke University Press, Durham.

Poppelaars, C. 2007, 'Resource Exchange in Urban Governance: One the Means that Matter', Urban Affairs Review, vol.43, no.1, pp.3-27

Queensland Chinese Forum (QCF) 2006, 昆士蘭華人論壇創立的主旨及目標 (The Aims and Objectives: For which the Queensland Chinese Forum is established), Private Collection.

Queensland Chinese United Council (QCUC) 2005, Constitution for the Queensland Chinese United Council, Private Collection.

Sassen, S. 1991, The Global City: New York, London, Tokyo, Princeton University Press, Princeton.

Sassen, S. 2006, Territory, Authority, Rights: From Medieval to Global Assemblages, Princeton University Press, Princeton.

Stoker, G. 1998, 'Theory and Urban Politics', International Political Science Review, vol. 19, no.2, pp. 119-29

Stone, C. N. 1989, Regime Politics: Governing Atlanta, 1946-1988, University Press of Kansas, Lawrence, KS.

Stone, C. N. 2005 'Looking back to look forward: Reflections on urban regime analysis', Urban Affairs Review, vol.40, no.3, pp.309-41

Tian, M. C. 1998, 'The History of the Chung Wah Association 1909-25', Early Days, vol. 11, no. 4, pp. 496-509

Vertovec, S. 2009, Transnationalism, Routledge, New York.

Weber, M. 1946, 'Politics as a Vocation', in Gerth H. H. and Wright Mills C. (trans and eds) From Max Weber: Essays in Sociology, Oxford University Press, New York, pp. 77-128

Wickberg, E. 1994, 'Overseas Chinese Adaptive Organisations, Past and Present', in Skeldon, R. Reluctant Exiles?: Migration from Hong Kong and the New Overseas Chinese, ME Sharpe, New York, pp. 68-84

Wu, Y. 2005, 'Taiwan's Domestic Politics and Cross-Strait Relations', The China Journal, no. 53, pp. 35-60

Yeoh, B. S. A. and Willis, K. 2005, 'Singaporean and British Transmigrants in China and the Cultural Politics of 'Contact Zones', Journal of Ethnic and Migration Studies, vol. 31, no.2, pp. 269-85

Zhou, M. and Lin, M. 2005, 'Community Transformation and the Formation of Ethnic Capital: Immigrant Chinese Communities in the United States', Journal of Chinese Overseas, vol.1, no.2, pp. 260-284 